\title{
PENURUNAN TINGKAT STRES KELUARGA PASIEN SKIZOFRENIA MELALUI MINDFULNESS SPIRITUAL ISLAM
}

\author{
Medika Utama*, Meidiana Dwidiyanti, Diyan Yuli Wijayanti \\ Program Studi Magister Keperawatan, Universitas Diponegoro, Jl. Prof. Soedarto, Tembalang, Kec. Tembalang, \\ Kota Semarang, Jawa Tengah, Indonesia 50275 \\ *medikautama.mail@gmail.com
}

\begin{abstract}
ABSTRAK
Keadaan stres yang terjadi pada keluarga pasien skizofrenia akan dapat berpengaruh terhadap kualitas hidup keluarga dan berpengaruh terhadap kesembuhan pasien. Jika keadaan yang menyebabkan stres pada keluarga tidak dapat ditanggulangi dengan baik, maka pasien yang menderita skizofrenia tersebut akan mengalami lebih banyak penderitaan dan akhirnya dirawat berulang-ulang di rumah sakit tanpa menunjukan tanda-tanda membaik. Penelitian ini dilakukan untuk mengetahui pengaruh intervensi mindfulness spiritual Islam dalam mengatasi keadaan stres yang terjadi pada keluarga pasien skizofrenia. Stres yang terjadi pada keluarga pasien skizofrenia yang terjadi karena keluarga merasa terbebani dan kurangnya rasa penerimaan juga kesadaran terhadap keadaan pasien. Penelitian ini menggunakan quasy-experiment dengan rancangan pre test - post test control group design. Sampel atau responden dalam penelitian ini adalah anggota keluarga dari pasien dengan skizofrenia yang memenuhi keriteria inklusi berjumlah 50 responden yang terdiri dari 25 kelompok kontrol dan 25 kelompok intervensi. Berdasarkan hasil penelitian yang dihitung menggunakan uji statistic menggunakan mann-whitney test terdapat penurunan stres sesudah diberikan intervensi pada kelompok intervensi dan kontrol $(\mathrm{p}=0,000<0,05)$.Nilai mean rank intervensi sebesar 13,00 lebih kecil dibandingkan dengan nilai mean rank kontrol 38,00 berarti bahwa terdapat penurunan stres pada kelompok intervensi setelah diberikan intervensi.
\end{abstract}

Kata kunci: mindfulness spiritual Islam, skizofrenia, stres keluarga

\section{REDUCING STRESS LEVEL IN FAMILY MEMBERS OF PATIENTS WITH SCHIZOPHRENIA THROUGH ISLAMIC SPIRITUAL MINDFULNESS}

\begin{abstract}
Stressful conditions in family members of patients with schizophrenia will affect the quality of family life as well as the patient's recovery. If such conditions are not properly managed, the patients may experience more suffering and readmission without any signs of improvement. Stress in the family members of patients with schizophrenia occurs due to the family burden and the lack of acceptance as well as the awareness of the patient's condition. The purpose of this study was to determine the effects of Islamic spiritual mindfulness on decreasing stress in family members of patients with schizophrenia. This study used a pretest-posttest quasi-experimental design with a control group. The samples were 50 families of patients with schizophrenia who met the inclusion criteria, and were assigned to the intervention group $(n=25)$ and the control group $(n=25)$. Based on the results of the Mann-Whitney test, it was found that there was a decrease in stress after the implementation of Islamic spiritual mindfulness in the intervention and control groups $(p=0.000<0.05)$. The mean value of stress in the intervention group was 13.00 while in the control group was 38.00 indicating that there was a decrease in stress in the intervention group after the intervention. The Islamic spiritual mindfulness gaveeffects on reducing stress in family members of patients with schizophrenia.
\end{abstract}

Keywords: family stress, schizophrenia, islamic spiritual mindfulness

\section{PENDAHULUAN}

Tingkat readmision yang terjadi pada pasien skizofrenia berkaitan dengan penerimaan yang terjadi didalam keluarga pasien tersebut. Rekam Medik RSJD Dr. Amino Gondohutomo Semarang mencatat selama tahun 2018 terdapat 308 kasus readmisison terjadi pada pasien yang kurang dali rentang waktu satu bulan.(RM RSJD Dr. Amino Gondohutomo. 2019)Keluarga merupakan sebuah pintu awal dari setiap perubahan. Jika terdapat satu gangguan didalam keluarga tersebut maka dapat mempengaruhi semua yang ada didalamnya.(Jusnita \& Hidajat, 2013) 
Keluarga melihat orang yang dicintai terdiagnosa sebuah penyakit akan merasa lebih banyak tertekan perasaannya dari pada pasien itu sendiri.(Wanti, Widianti, \& Fitria, 2017) Stres merupakan efek paling umum yang sering dirasakan oleh keluarga dari pasien yang menderita penyakit tertentu yang membutuhkan waktu yang lama untuk penyembuhannya. Keadaan tersebut dapat berpengaruh terhadap kualitas hidup keluarga dan pasien itu sendiri kedepannya.(Zhang, Xu, Wang, \& Wang, 2016)

Keluarga pasien skizofrenia dapat menjadi tertekan dengan keadaan yang dialami oleh pasien. Pasien membutuhkan perawatan di rumah oleh keluarga, stigma dari masyarakat yang memandang buruk penyakit skizofrenia.(Koschorke et al., 2017)Penelitian sebelumnya menyatakan stres yang terjadi pada keluarga pasien skizofrenia berupa perasaan tertekan karena lelah dengan keadaan pasien yang membutuhkan perawatan didalam keluarga, perasaan jenuh, perasaan malu dengan keadaan yang terjadi pada pasien, merasa didiskriminasi di lingkungan masyarakat, dan merasa terisolasi dari lingkungan karena stigma masyarakat tentang penyakit skizofrenia yang masih buruk.(Adeosun, 2013)

Penelitian yang sudah dilakukan dan dipublikasikan untuk mengatasi keadaan stres menggunakan intervensi mindfulness spiritual Islam sejauh ini adalah pengaruh intervensi mindfulness spiritual Islam terhadap tingkat stres mahasiswa dengan hasil penelitian menunjukkan bahwa mindfulness spiritual Islam signifikan mnurunkan keadaan stres yang terjadi.(Munif, Poeranto, \& Utami, 2019) Penelitian untuk mengatasi tingkat stres di area yang lebih luas terutama pada keluarga pasien skizofrenia menggunakan intervensi mindfulness spiritual Islam belum pernah dilakukan penelitian. Melalui penelitian ini, peneliti akan menggunakan intervensi mindfulness spiritual Islam untuk mengatasi keadaan stres yang terjadi pada keluarga pasien skizofrenia.

Stres yang terjadi pada keluarga pasien skizofrenia yang terjadi karena keluarga merasa terbebani dan kurangnya rasa penerimaan juga kesadaran terhadap keadaan pasien. Stigma dari masyarakat yang masih buruk juga memperkuat keadaan stres yang dialami oleh keluarga.(Yusuf, 2017) Hal ini sejalan dengan teori Lazarus yang mengatakan bahwa tingginya tuntutan terhadap lingkungan yang tidak mampu dipenuhi oleh individu,(Lazarus, 1993)hal ini terjadi pada keluarga pasien skizofrenia. Keadaan tertekan dan kurangnya rasa penerimaan yang terjadi pada keluarga akan menyebabkan keluarga memaknai keadaan tersebut merupakan sebuah beban dan aib bagi keluarga.(Wiguna et al., 2015)

Intervensi mindfulness merupakan bagian dari keperawatan holistik yang mempunyai konsep mengikuti kebutuhan dari budaya dan kebiasaan dari lingkungan masyarakat.(Dwidiyanti, Wiguna, Pamungkas, \& Wahyu, 2019)Mindfulness spiritual Islam akan membantu keluarga pasien skizofrenia secara sadar dalam memahami bagaimana kondisi yang sedang terjadi pada saat ini, meningkatkan rasa penerimaan terhadap semua keadaan tanpa memberikan penilaian berlebihan. Menumbuhkan kesadaran bahwa setiap kejadian bukanlah sebagai sebuah kebetulan, semua yang terjadi adalah ketentuan dari Allah SWT dan bagaimana keluarga akan menyikapi dan menemukan solusi dari keadaan tersebut tanpa memberikan sebuah reaksi yang berlebihan karena tidak ada sedikitpun kejadian yang bukan dari Allah bahkan untuk keadaan sulit sekalipun.(Dwidiyanti, 2019)Dalam dunia keperawatan, keadaan stres merupakan sebuah permasalahan yang berkelanjutan. Penerapan sebuah intervensi keperawatan untuk mengatasi masalah tersebut membutuhkan pendekatan khusus terhadap respon psikologis pasien.(White, 2013). Tujuan dari penelitian ini adalah untuk mengetahui pengaruh dari intervensi mindfulness spiritual Islam terhadap tingkat stres dari keluarga pasien skizofrenia menggunakan jenis penelitian quasiexperimental dengan rancangan pre test - post test control group design.

\section{METODE}

Penelitian ini merupakan penelitian kuantitatif menggunakan desain quasi-experimental dengan rancangan pre test - post test control group designyang membandingkan nilai pengukuran awal (pre-test) dengan pengukuran akhir (post-test) tingkat stres pada keluarga pasien skizofrenia yang dilakukan pada kelompok intervensi dan kelompok kontrol penelitian. 
Sampel atau responden dalam penelitian ini adalah keluarga inti dari pasien skizofrenia yang memenuhi keriteria inklusi yaitu muslim berdasarkan data dari keluarga pasien skizofrenia., anggota keluarga inti dari pasien skizofrenia yang berumur $\geq 18$ tahun, mampu berkomunikasi dengan baik, membaca dan menulis, dan tinggal serumah dengan pasien minimal 5 bulan terakhir. Pengambilan responden dalam penelitian ini menggunakan prosedur nonprobability sampling dengan teknik penetapan pada responden mengunakan purposive sampling. Penghitungan jumlah minimal responden yang akan digunakan dalam penelitian ini berdasarkan acuan data dari literatur penelitian sebelumnya mengenai pengaruh terapi mindfulness terhadap stres dimana jumlah responden ditentukan menggunakan metode power size dan effect size berdasarkan Cohen. Penelitian ini menggunakan table $\alpha=0.05$ dengan power size 0.80 dan effect size 0.80 sehingga ditetapkan sample berjumlah 25 kelompok intervensi dan 25 kelompok kontrol. Jumlah keseluruhan responden penelitian pada penelitian ini sebanyak 50 responden.

Penelitian ini menggunakan kuesioner Depression Anxiety Stress Scale (DASS) yang dikembangkan oleh Lovibond. Kuesioner dirilis secara resmi oleh Psychology Foundation Australia dengan bentuk kuesioner yang sudah baku berisi 42 item pertanyaan.(Lovibond \& Lovibond, 1995)
Pada penelitian ini kuesioner digunakan untuk mengukur tingkat stres yang terjadi pada keluarga pasien skizofrenia. Proses penelitian ini telah dilakukan selama 3 bulan (JuliSeptember 2019).

Seluruh responden sebanyak 50orang berpartisipasi dari proses awal hingga proses akhir penelitian dengan pertemuan untuk intervensi sebanyak 3 kali sebelum dilakukan pengukuran ulang tingkat stres yang terjadi untuk mengetahui perubahan kepada keluarga saat sebelum dilakukan intervensi. Intervensi dilakukan kepada keluarga selama priode penelitian dan tingkat stres diukur menggunakan kuesioner yang sama saat pretest pos-test. Penelitian dilakukan kepada keluarga inti dari pasien skizofrenia yang dirawat di RSJD Dr. Amino Gondohutomo Provinsi Jawa Tengah setelah dinyatakan lulus uji etik dari Komite Etik Proposal Penelitian RSJD Dr. Amino Gondohutomo Provinsi Jawa Tengah dengan nomor: 420/1/0418.

\section{HASIL}

Penulis menguraikan hasil penelitian berdasarkan urutan tujuan penelitian yang sudah direncanakan. Hasil yang sudah didapatkan selama penelitian dilakukan uji statistik menggunakan komputer untuk melihat pengaruh yang terjadi terhadap kelompok intervensi dan kelompok kontrol. Hasil dari penghitungan diuraikan dalam tabel berikut.

Tabel 1.

Tingkat stres keluarga sebelum dan sesudah di lakukan intervensi pada kelompok intervensi dan kelompok kontrol

\begin{tabular}{lcccc}
\hline \multirow{2}{*}{ Variabel } & \multicolumn{2}{c}{ Intervensi $(\mathrm{n}=25)$} & \multicolumn{2}{c}{ Kontrol $(\mathrm{n}=25)$} \\
& $\mathrm{f}$ & $\%$ & $\mathrm{f}$ & $\%$ \\
\hline Pre-test & 0 & 0 & 0 & 0 \\
Normal & 5 & 20 & 17 & 68,0 \\
Ringan & 20 & 80,0 & 8 & 32,0 \\
\hline Sedang & & & & \\
Post-test & 25 & 100,0 & 0 & 0 \\
Normal & 0 & 0 & 17 & 68,0 \\
Singan & 0 & 0 & 8 & 32,0 \\
\hline
\end{tabular}

Tabel 1 menunjukkan tingkat stres yang terjadi pada responden penelitian yaitu keluarga dari pasien skizofrenia yang dirawat di RSJD Dr.
Amino Gondohutomo Provinsi Jawa Tengah pada saat pre-test dan post-test. 
Tabel 2.

Hasil uji tingkat stres keluarga sebelum dan sesudah di lakukan intervensi pada kelompok intervensi dan kelompok kontrol.

\begin{tabular}{|c|c|c|c|c|c|c|}
\hline & \multirow{2}{*}{$\begin{array}{c}\text { Mean } \\
\text { Difference }\end{array}$} & \multicolumn{2}{|c|}{ Sebelum } & \multicolumn{2}{|c|}{ Sesudah } & \multirow[b]{2}{*}{$p$} \\
\hline & & Mean $\pm S D$ & Min-Max & Mean $\pm S D$ & Min-Max & \\
\hline Intervensi & 14,24 & $20,36 \pm 2,31$ & $15-24$ & $6,12 \pm 2,54$ & $1-11$ & 0,000 \\
\hline Kontrol & 5,28 & $17,04 \pm 2,17$ & $15-22$ & $17,04 \pm 1,93$ & $15-22$ & 1,000 \\
\hline
\end{tabular}

Berdasarkan data dari hasil penghitungan pada tabel 2 menggunakan wilcoxon testterdapat perbedaan tingkat stres dari kelompok intervensi pada saat penghitungan tingkat stres sebelum dan sesudah dilakukan intervensi, pada kelompok kontrol tidak menunjukan perubahan tingkat stres yang terjadi.

Tabel 3.

Pengaruh intervensi terhadap tingkat stres keluarga pasien skizofrenia antara kelompok intervensi dan kelompok kontrol

\begin{tabular}{llccccc}
\hline & & \multicolumn{2}{c}{ Intervensi } & \multicolumn{2}{c}{ Kontrol } & \multirow{2}{*}{$p$} \\
\cline { 3 - 6 } & & Mean Rank & Sum Rank & Mean Rank & Sum Rank & \\
\hline \multirow{2}{*}{ Tingkat Stres } & Sebelum & 34,12 & 853,00 & 16,88 & 422,00 & 0,000 \\
& Sesudah & 13,00 & 325,00 & 38,00 & 950,00 & 0,000 \\
\hline
\end{tabular}

Berdasarkan penghitungan dari data yang diperoleh pada tabel 3 menggunakan mannwhitney test dapat disimpulkan bahwaterdapat perbedaan tingkat stres sebelum diberikan intervensi pada kelompok intervensi dan kontrol.

\section{PEMBAHASAN}

Berdasarkan hasil uji statistik dari penelitian yang sudah dilakukan, kelompok intervensi dilakukan pengukuran tingkat stres menggunakan kuesioner DASS pada saat pretest atau sebelum dilakukan intervensi. Hasil pada pengukuran tingkat stres yang dilakukan pada kelompok intervensi berada pada tingkat stres sedang sebanyak 20 orang $(80,00 \%)$ dan 5 orang responden mengalami stres ringan. Sesudah diberikan 3 kali intervensi, kelompok dilakukan pengukuran ulang atau post-test dan mendapatkan hasil pengukuran tingkat stres berada pada stres normal sebanyak 25 orang $(100,0 \%)$.

Pada kelompok kontrol saat dilakukan pengukuran tingkat stres awal atau pre-test didapatkan hasil tingkat stres berada pada stres ringan sebanyak 17 orang $(68,0 \%)$ dan stres sedang sebanyak 8 orang $(32,0 \%)$. Saat dilakukan pngukuran berikutnya atau post-test, kelompok kontrol ini tidak menunjukkan perubahan yang terjadi yaitu berada pada tingkat stres yang sama dengan hasil tingkat stres ringan sebanyak 17 orang $(68,0 \%)$ dan tingkat stres sedang sebanyak 8 orang $(32,0 \%)$.
Berdasarkan hasil penelitian yang dihitung menggunakan uji statistic menggunakan mann-whitney test dapat disimpulkan bahwa terdapat perbedaan tingkat stres sesudah diberikan intervensi pada kelompok intervensi dan kontrol $(p=0,000<0,05)$. Dari hasil uji dapat disimpulkan bahwa terdapat pengaruh intervensimindfulness dalam menurunkan stres keluarga pasien skizofrenia. Nilai mean rank intervensi sebesar 13,00 lebih kecil dibandingkan dengan nilai mean rank kontrol 38,00 berarti bahwa terdapat penurunan stress pada kelompok intervensi setelah diberikan intervensi.

Hasil dari penelitian ini sejalan dengan teori Lazarus bahwa kondisi stres akan terjadi pada saat idividu memaknai sebuah stresor yang sedang berlangsung.(Alligood Raile, 2014) Keluarga pasien skizofrenia akan mengalami keadaan stres pada saat dirinya menilai bahwa keadaan yang terjadi adalah sebuah beban yang mengancam kehidupan mereka. Bentuk evaluasi sebagai hasil dari proses penilaian terhadap stresor melalui penilaian primer dan sekunder menurut Lazarus antara lain: penilaian tidak relevan, penilaian positif, dan stres.(Lyon, 2012)

Penilaian stres menghasilkan tiga kondisi pada individu tersebut bagaimana pandangan individu melihat keadaan yang sedang terjadi. Pandangan tersebut adalah harm, treat, dan chalengge.(Lumban Gaol, 2016)Harm 
merupakan penilaian kepada sebuah keadaan bahwa keadaan tersebut dapat membahayakan individu, treat merupakan penilaian terhadap keadaaan yang membahayakan tersebut dapat kembali berlanjut dikemudian hari, dan challenge merupakan penilaian terhadap keadan bahwa keadaan tersebut adalah sebuah tantangan dan harus harus dihadapi oleh individu.(Lazarus, 1993)

Strategi positive reappraisal dalam menanggulangi stresmenurut Lazarus dapat dilakukan dengan cara melibatkan beberapa hal bersifat religius untuk pengembangan diri.(Pei, Chai, Shepherd, \& Billington, 2010)Sifat religius untuk pengembangan diri dapat juga dikatakan sebagai koping spiritual. Sifat religius merupakan sebuah penggunaan keyakinan dalam agama yang dianut untuk memecahkan sebuah permasalahan yang dihadapi, melakukan pencegahan, dan mengurangi dampak negatif dari sebuah keadaan emosional dari sebuah kehidupan.(Ano \& Vasconcelles, 2005)Dalam mindfulness spiritual Islam, tawakal membantu dalam menerima kesungguhan hati dan berserah diri kepada Allah.(Dwidiyanti, 2019)Keluarga pasien skizofrenia akan dibantu menyerahkan seluruh permasalah yang terjadi kepada Allah tanpa menghawatirkan lingkungan sekitarnya untuk menghindari stres yang terjadi. Keluarga akan mampu menerima bagaimanapun keadaan pasien karena keluarga sudah meyakini bahwa semanya adalah kehendak Allah.

Intervensi mindfulness spiritual Islam yang diberikan kepada keluarga pasien skizofrenia ini mempunyai tujuan untuk membantu individu secara sadar memahami bahwa semua kondisi yang dialami pada saat ini adalah bukan karena sebuah kebetulan tetapi sudah ditentukan oleh Allah.(Dwidiyanti et al., 2019)Tujuan berikutnya adalah membantu individu menemukan ketenangan atas semua keadaan dan mampu menemukan solusi terhadap permasalahan sesuai aturan agama Islam secara mandiri, juga menentukan target sehat mandiri agar apapun yang terjadi nantinya tidak akan membebani pikiran secara berlebihan. Dwidiyanti (2019) Spiritualitas yang baik akan meningkatkan dalam hal penerimaansetiap keadaan, kesabaran, serta keikhlasan untuk menganggap bahwa semua ini sudah menjadi ketentuan dari Tuhan.(Lazaridou \& Pentaris, 2016)

\section{SIMPULAN}

Terdapat penurunan tingkat stres pada kelompok intervensi daripre-testhingga posttest, maka dapat disimpulkan bahwa terdapat pengaruh intervensi mindfulness spiritual Islam dalam menurunkan tingkat stres keluarga pasien skizofrenia.

\section{DAFTAR PUSTAKA}

Adeosun, I. I. (2013). Correlates of Caregiver Burden among Family Members of Patients with Schizophrenia in Lagos, Nigeria. Hindawi Publishing Corporation, $7, \quad 1-7$. https://doi.org/http://dx.doi.org/10.1155/ 2013/353809

Alligood Raile, M. (2014). Nursing Theorists And Their Work (8th ed.). St. Louis, Missouri: United States of America: Elsevier Mosby.

Ano, G. G., \& Vasconcelles, E. B. (2005). Religious Coping and Psychological Adjustment to Stress : A Meta-Analysis. Journal Of Clinical Psychology, 61(4), 461-480.

https://doi.org/10.1002/jclp.20049

Dwidiyanti, M. (2019). The Art of Mindfulness Spiritual Islam (1st ed.). Semarang: UNDIP Press.

Dwidiyanti, M., Wiguna, R. I., Pamungkas, A. Y., \& Wahyu, H. E. (2019). Concept analysis of mindfulness based on islam religion. Jurnal Ilmu Keperawatan, 6(2), 22-30. https://doi.org/ISSN: 23386371, e-ISSN 2550-018X

Jusnita, N., \& Hidajat, L. (2013). Profil Kepribadian dan Psychological WellBeing Caregiver Skizofrenia. Jurnal Soul, 6(1), 20-42. Retrieved from http://www.ejournal-

unisma.net/ojs/index.php/soul/article/vie w/735

Koschorke, M., Padmavati, R., Kumar, S., Cohen, A., Weiss, H. A., Chatterjee, S., ... Thornicroft, G. (2017). Social Science \& Medicine Experiences of 
stigma and discrimination faced by family caregivers of people with schizophrenia in India. Social Science \& Medicine, $\quad 178, \quad 66-77$. https://doi.org/10.1016/j.socscimed.201 7.01 .061

Lazaridou, A., \& Pentaris, P. (2016). Mindfulness and spirituality: therapeutic perspectives. PersonCentered \& Experiental Psychoterapies, 15(3), 1-10. https://doi.org/10.1080/14779757.2016. 1180634

Lazarus, R. S. (1993). From Psychological Stress To The Emotions : A History of Changing Outlooks. Annual Review of Psychological, 44(1), 1-22. Retrieved from http://www.annualreviews.org

Lovibond, S. ., \& Lovibond, P. . (1995). Depression Anxiety Stress Scales (DASS-42). Psychology Foundation of Australia. $\quad$ Sydney: Psychology Foundation. https://doi.org/10.1097/HTR.000000000 0000250

Lumban Gaol, N. T. (2016). Teori Stres : Stimulus, Respons, dan Transaksional. Buletin Psikologi, 24(1), 1-11. https://doi.org/10.22146/bpsi.11224

Lyon, B. L. (2012). Stress, Coping, and Health (2nd Ed). United States of America: SAGE Publication Inc.

Munif, B., Poeranto, S., \& Utami, Y. W. (2019). Effects of islamic spiritual mindfulness on stress among nursing students. Nurse Media Journal of Nursing, $\quad 9(1), \quad 69-77$. https://doi.org/10.14710/nmjn.v9i1.2225 3

Pei, P., Chai, M., Shepherd, D., \& Billington, R. (2010). How Religious Coping is Used Relative to Other Coping Strategies Depends on the Individual 's Level of Religiosity and Spirituality. Journal of Religion and Health, 51, $1137-1151$

https://doi.org/10.1007/s10943-010-

9416-x
Rekam Medis RSJD Dr. Amino Gondohutomo. Index 10 Besar ICD Periode 2018 - 2019. (2019). Semarang.

Wanti, Y., Widianti, E., \& Fitria, N. (2017). Gambaran Strategi Koping Keluarga dalam Merawat Anggota Keluarga yang Menderita Gangguan Jiwa Berat. Jurnal Keperawatan Padjadjaran, (April 2016). https://doi.org/10.24198/jkp.v4n1.9

White, L. (2013). Mindfulness in nursing: an evolutionary concept analysis. Journal of Advance Nursing, 70(2), 282-294. https://doi.org/10.1111/jan.12182

Wiguna, T., Irawati, R., Noorhana, S. R., Kaligis, F., Nugrahaning, A., \& Belfer, M. L. (2015). Family responses to a child with schizophrenia: An Indonesian experience. Asian Journal of Psychiatry. https://doi.org/10.1016/j.ajp.2015.09.00 9

Yusuf, A. (2017). Terapi Keluarga Dengan Pendekatan Spiritual Terhadap Model Keyakinan Kesehatan Keluarga Dalam Merawat Pasien Skizofrenia. Jurnal Ners, $\quad 8(1), \quad 165-173$. https://doi.org/10.20473/jn.v8i1.3897

Zhang, J., Xu, R., Wang, B., \& Wang, J. (2016). Effects of mindfulness-based therapy for patients with breast cancer: A systematic review and meta-analysis. Complementary Therapies in Medicine, 26(35), 1-10. https://doi.org/10.1016/j.ctim.2016.02.0 12 